Urban Water Systems \& Floods II 91

\title{
PLANNING OPPORTUNITIES FOR CLIMATE RESILIENCE IN BRISBANE, AUSTRALIA: LEARNING FROM THE CITY'S HISTORY OF FLOODS
}

\author{
TOMAS BRAGE \& PAOLA LEARDINI \\ School of Architecture, The University of Queensland, Australia
}

\begin{abstract}
South East Queensland, in Eastern Australia, is a region naturally prone to flooding. While this intrinsic hydrologic characteristic of the area was well known to its aboriginal inhabitants, its urbanisation is less than two hundred years old and has proven greatly oblivious to the natural environment. In Brisbane, the capital city of the State of Queensland, the clash between natural processes of the namesake river, its numerous creeks and the sea, and the superimposed layer of the urban fabric has recurrently played out since the foundation of the colony, in 1824, with the last disastrous event occurring in 2011 at a tremendous human and material cost. This paper analyses the nature of this difficult relationship between water as a dynamic force and the city of Brisbane as a static, yet ever expanding, presence, from a historical, geographical and social point of view. The aim is to identify opportunities that lay dormant in this relationship since its prehistory and can be harnessed to make the future city resilient to its geographical and climatic context, by embracing urban planning and management approaches that are sensitive to, and compatible with the deep structure of the city and its territory. Based on findings of this multifaceted analysis the paper recommends the application of longterm, adaptable planning that is framed according to climate cycles and climate change forecasts, a multidisciplinary, integrated way of understanding flooding, and a coordinated and transparent decision-making process that includes all institutions and stakeholders beyond individual interests.

Keywords: Aboriginal, climate, environment, floods, geography, knowledge, planning, resilience, river.
\end{abstract}

\section{INTRODUCTION}

The geographical context of a city explains much of its history and defines to a large extent its character, culture and the challenges it faces [1]-[4]. Regional and urban planning must recognise the variety of aspects of the territory occupied by urban areas, what has been called its deep structure [5]. The main aspect of geography in its consequences for life is climate, affecting temperatures, availability of water, food and other resources [6]. At its most dramatic expression, extreme climate events periodically shake the foundations of many cities worldwide, and in particular floods represent one of the most disruptive kinds of natural disasters for cities [7]. The south east of the state of Queensland (SEQ), in Australia, pertaining to its location on the edge of a very large continental mass and subject to subtropical climate phenomena, is a region prone to droughts, bushfires and multiple types of flooding, a situation likely to worsen due to climate change [8].

Adequate knowledge of the geographical context and the existence of public awareness of such natural hazards, especially floods, constitute therefore a precondition for climate resilience in SEQ and specifically in Brisbane, the capital of the State of Queensland. Traditional ecological knowledge of the Aboriginal people can help unveil realities worth considering for the future-proofing of urban areas. Aboriginal peoples have lived in Australia for some 50,000 years or even longer [9] and have since their arrival modified the environment greatly. However, they also accumulated extensive ecological knowledge over this relatively stable long period - Aboriginal people never made the transition to agricultureand their isolation, given that their culture was not greatly disturbed from outside of Australia until the arrival of Europeans in the nineteenth century [10]. In addition to Aboriginal orally- 
transmitted ecological knowledge, there are now precise records of flood and drought events since the first European settlement of the region in 1824. These two sources of knowledge, together with the collective memory of floods in the region provide evidence for the study of the recent climate history of Brisbane and the attitudes of its inhabitants relative to it. This complements scientific research that has and will continue to describe the environmental characteristics of the region in detail [8], [11]. It is evident though, that the new urban culture laid on the Brisbane river plains stands in contrast to the ancient Aboriginal culture and is based on a very modest understanding of the broader geographical and historical space in which the city has grown. In this context, a laissez-faire attitude toward urban development has only as recently as the 1990s generated sufficient interest toward regional planning [12].

The history of Brisbane and its floods is discussed in this paper with the objective of extracting general ideas and strategies that could inform climate-resilient urban planning and design in the city. Urban climate-resilience includes social and structural -physical- aspects, and implies three basic properties: persistence of basic components and functions, adaptability to moderate change through time, and flexibility to rapidly transform nonadaptive systems [13]. Knowledge of general climate-resilience criteria, but also of local specificities affecting Brisbane is a prerequisite for achieving greater climate resilience in the city. The robustness of a climate-resilience scheme that includes long-term, evidence-based considerations also depends on an understanding of urban social realities; this ensures that interventions are sensitive to social perceptions and expectations, and decision-making involves public participation and awareness and a sense of ownership of policies and planning schemes [14].

\section{BRISBANE'S GEOGRAPHICAL SETTING}

\subsection{Brisbanes deep structure}

The SEQ region is a subtropical forested river basin characterised by large flood plains and fringe ridges. It is rich in river and water systems that harbour very high biodiversity, as a result of being at the confluence of subtropical and temperate ecological regions. This node is known as the Macleay-McPherson overlap, and stands out ecologically in, for example, the large number of endemic species it hosts [15]-[17]. The whole region can be seen as an ecotone, or hinge ecosystem, where river catchments, the coast and sub-tropical and temperate bioregions concur (Fig. 1). Its climate is dominated by subtropical wet-and-dry regimes, in which river streamflow is dominated by tropical weather systems [11]. SEQs subtropical climate is characterised by long periods of drought followed by wet years where big-flood recurrence is much higher. Yearly, its seasonal regime consists of a hot wet season followed by a long warm and relatively dry season. The El Niño-Southern Oscillation, coupled with the Pacific Decadal Oscillation produces unusual levels of climatic uncertainty and high frequency of extreme events as flooding, droughts, cyclones, storms and bushfires [18]. In addition, Queensland is believed to be the Australian state with the highest vulnerability to climate change [19], where even more common extreme-weather events, higher climatic variability, and accelerated sea level rise are predicted. In general, for SEQ, climate change is expected to intensify and extend the periods of drought, interspersed with more extreme episodes of rain and consequent flooding [8].

The longest river in the region is the Brisbane river [11], [20], which flows from southwest to north-east drawing long meanders [21]. There exist a total of two dams in the catchment: the Somerset dam and the greater Wivenhoe dam [22] (Fig. 2). 


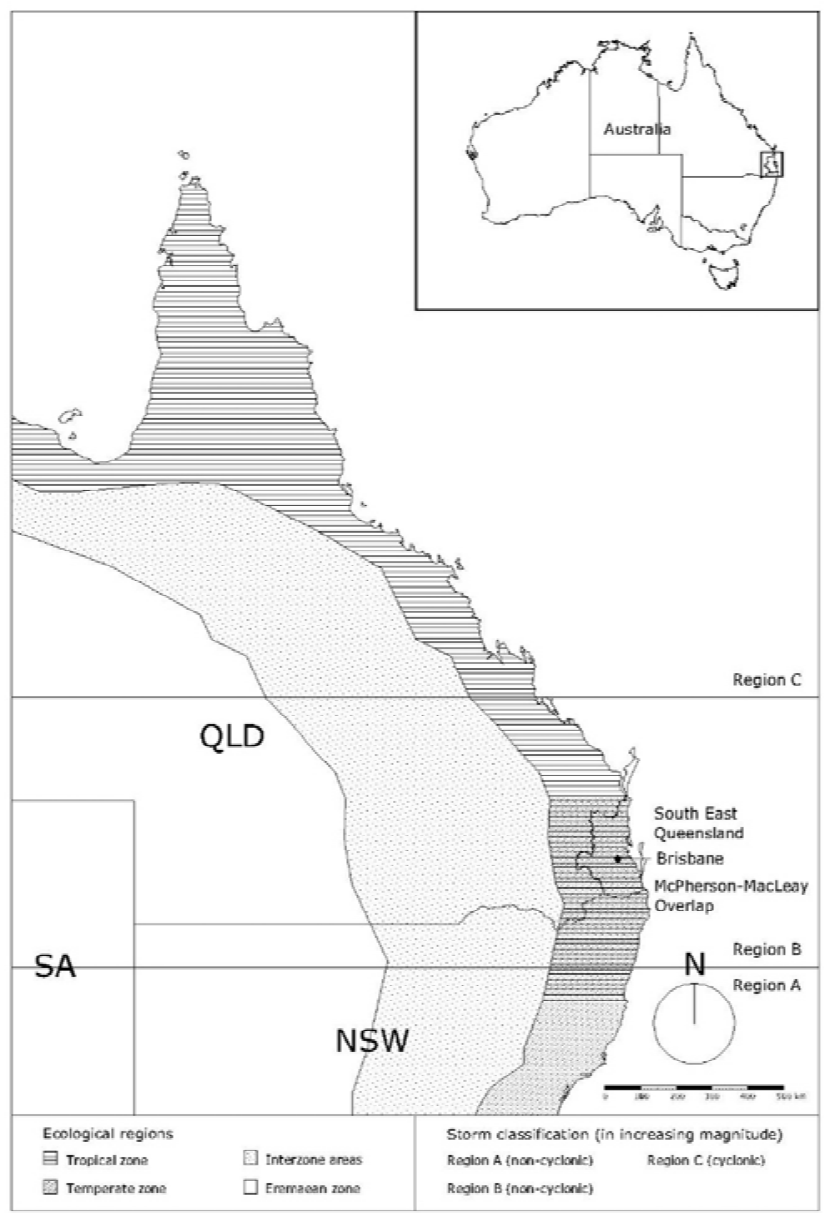

Figure 1: South East Queensland regional setting: ecological regions and storm regions.

In terms of the geomorphology of Brisbane's river system it must be noted that it is not very well studied, as Geomorphological studies in Australia are relatively new. in particular, research on Australian fluvial systems only started in the second half of the twentieth century [23]. Crucially for many river systems in Queensland, subtropical river dynamics are not as well understood as temperate fluvial systems [11], so a higher degree of uncertainty needs to be accounted for when considering the behaviour of the Brisbane river, compared to other rivers in temperate regions of Australia and the world.

\subsection{The Brisbane river system}

Flooding is an essential component of any natural fluvial system, but the resilience of rivers to large floods varies depending upon a series of factors. The Brisbane river pattern has remained stable since pre-colonial times, in contrast to rivers in temperate Australia, due to decadal return in large floods, instead of annual and biannual flood return interval in 


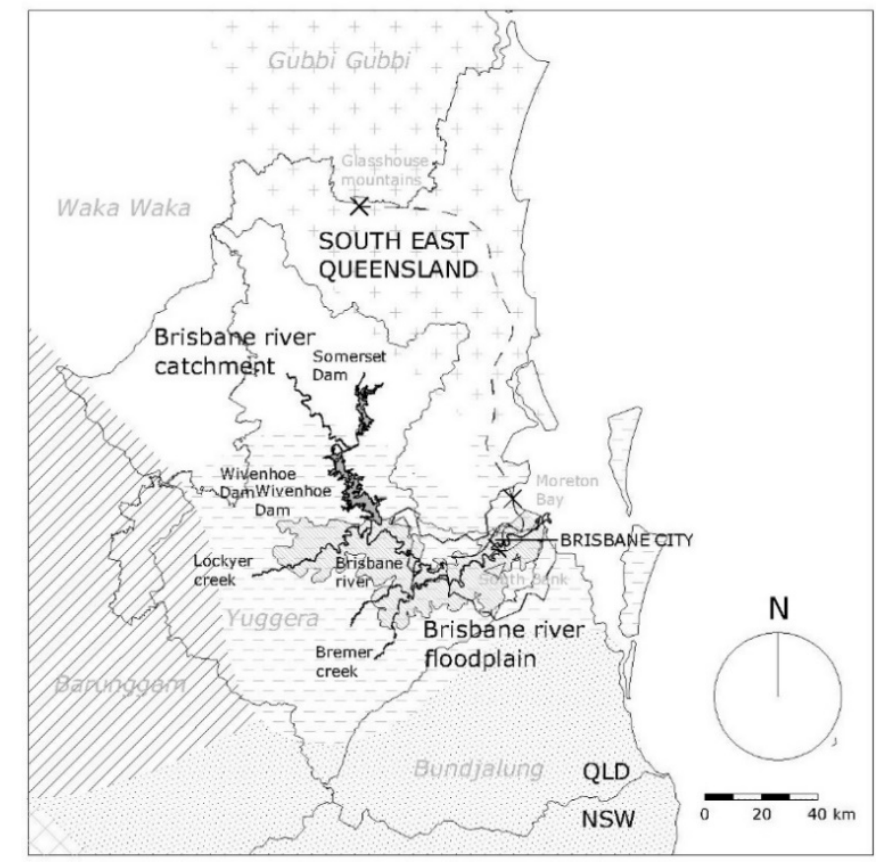

Figure 2: The South East Queensland region: Aboriginal territory; Brisbane river catchment and floodplain, and modern administrative boundaries.

temperate areas. The large macrochannels that makes these rivers resilient to high magnitude floods suggest that exceptionally big floods in the past set them in a stable state. For example, a catastrophic flood dating 270 years before present has been found to be responsible for the capacity and position of Lockyer Creek's macrochannel [8], [11], [24].

Since European settlement in the 1840 s, agriculture practices and urbanisation in the Brisbane catchment enhanced river channel erosion as native vegetation cover was removed and replaced by crops, grassland or impervious surfaces. Further, land was typically drained, and sheep and cattle farming introduced. Findings show that riparian vegetation in particular is fundamental for maintaining channel stability in the Brisbane river, and that most changes observed in the river since European settlement to the present are derived from land clearing the 19th century, showing considerable time-lag [11], [25]. Moreover, undeveloped banks along the Brisbane river have been recognised as one the most important natural assets that are still preserved in the city [26], which in conjunction with their significance for flood mitigation, reinforces the importance of conserving the river system in the most natural state possible. This is in line with the present understanding of urban sustainability, that identifies riparian corridors as one of the crucial habitats to be protected in urban environments [27].

\section{THE ABORIGINAL PEOPLE AND THE BRISBANE RIVER}

Aboriginal peoples in Australia have practised various degrees of nomadism and have never established hard boundaries. Their territories were nevertheless marked, natural features being usually enough to recognise specific "countries". Landscapes were intimately associated with their productive characteristics and very significantly with the presence of water, both as a resource and as a hazard. Knowledge of the territory was vital in organising 
seasonal movements and it was celebrated and transmitted in periodical gatherings where different tribes met and shared local resources, experiences and information. For example, seasonal events coincided with the migration of sea mammals at Moreton Bay or the Araucaria seed production season in the Glass House Mountains (P. Memmott, personal communication, July 5, 2017) (Fig. 2). Both the passage of time and physical space were fundamental in their understanding of the world which was thereby highly dynamic and fluid. The lives of the aboriginal people were so intertwined with their natural environment that it may be argued that the divide between the environment and those who inhabit it was somewhat diffuse [28].

Aboriginal people organised themselves in groups of similar size that occupied a territory of variable area depending on the availability of resources (P. Memmott, personal communication, July 5, 2017). The extent of the area of influence of each tribe was intentionally ambiguous, with overlaps and communal zones being typical. The Brisbane river was one of these zones: called Mairwar, was a "transient and communal...natural highway" [15] for Jagarra and Quandamooka people. Turrbal and possibly Yuggera tribes considered the area as their own, so they were more used to act as hosts for visiting peoples than other groups. It seems that owing to the communal character of the Brisbane River, European settlement on the north bank at the site of the current CBD was not conflictive, as it was the 1824 settlement on the coast at Redcliffe in relation to the Ningy-Ningy people [15].

Aboriginal people did not build urban centres beyond villages or camps. The evidence of camps in the Brisbane region is unfortunately scarce, but there exist accounts by early European explorers of camps along the Brisbane river and even a fish and bark market on the south bank of the river (P. Memmott, personal communication, July 5, 2017).

Throughout Australia relatively stable gathering and cult spaces existed and were commonly situated near sources of fresh water, on lookouts or "crossroads" at places with a benign microclimate and safe from natural hazards These symbolic places did not assume the form of built structures identifiable as settlements and little of them remains [10]. Despite their lack of urban structures, Aboriginal people did alter the lands they occupied. As in other parts of Queensland [25], the modification of the Brisbane river basin occurred through firestock farming: the clearance of forest by controlled fires, in order to attract grazing prey that aboriginal people hunted. Wetlands were also appreciated by aboriginal people for they make for good hunting grounds, so they had a strong incentive to conserve them. Transport on the river was done by means of canoes or by swimming at particular crossings [15]. In summary, the very long history of Aboriginal interaction with the territory made them culturally aware of the importance of maintaining the integrity of the environment and to avoid natural hazards.

\section{URBAN DEVELOPMENT HISTORY OF BRISBANE}

In 1824, the European settlement of the Brisbane river catchment began and a stable settlement was established around the present-day Brisbane CBD [21], [26], high above the river in order to avoid it being washed away by floods [19]. Soon after, Brisbane was declared port of entry. Since then it has seen increasing populations in a continuous migratory influx, with some distinct waves, first in the 1880 s, then in the post-war decades of the twentieth century [21]. The latest has been the recent interstate migration, rendering SEQ Australia's most rapidly growing region [19]. In the first decades after the foundation of the city, vulnerable low-lying areas were occupied by worker cottages while wealthier families built their houses on the overlooking hills, safe from floods and with better climatic conditions [21]. However, following the 1893 floods, flood-prone areas were designated unfit for 
housing [12]. A modest industry was established along the river banks, and farther upstream Ipswich became an industrial hub concentrating coal shipping and railway services. Linking both cities, the Brisbane river hummed with activity until railway became hegemonic towards the end of the nineteenth century. [15].

Generally, the first decades of British settlement produced recognisable town grid layouts across Australia, a product of the high degree of authority of governors, that implemented strict policies developed through past experience in other colonies. This strong bureaucratic structure was eroded quickly and development soon outgrew town plans following the immigrants' thirst for new opportunities [10], [29]. This new laissez-faire paradigm persisted in the Australian federal government's historical lack of concern with urban morphology [30]. In Queensland in particular, governments have traditionally shown reluctance toward planning [21]. Although in 1925 Brisbane City Council became the most powerful local government in Australia to this day, when the Greater Brisbane was created (Fig. 2), this did not lead to a strengthening of the local planning structure. The rapid population growth and accompanying urbanisation experienced by the SEQ region during the second half of the twentieth century [12] (Fig. 3) happened largely in an unplanned fashion, attracting only spurious research interest, showing how little attention has been paid to urbanisation by politicians, planners and academics in the region [12]. In 1996 SEQ was already a low density, dispersed, fast growing polycentric mega region, relying on its network of highways, and public transport accounting for less than $10 \% \mathrm{~s}$ of work trips [26]. This growth model has continued in recent years, giving Brisbane one of the lowest densities of cities around the world [31]. Without an extensive network of National Parks to bound development, as in the case of Sydney, the region's urban areas have sprawled extensively on greenfields and floodplains [31]. Interest in apartment building in Brisbane only appeared in the 1990s [12], although following the market saturation of other state capitals, has considerably grown in recent years [32]. As a result, the green area per capita in the city has been steadily diminishing while access to the river has been impeded in many places, notably in the CBD by the system of freeway flyovers and underpasses, disconnecting a substantial portion of the city from its most valuable asset [33]. Showing novel awareness of the key role of spatial planning the state government finally released the first South East Queensland Regional Plan 2005, followed by the publication of the 2009 SEQ Regional Plan and the most recent SEQ Regional Plan 2017 [34], [35].

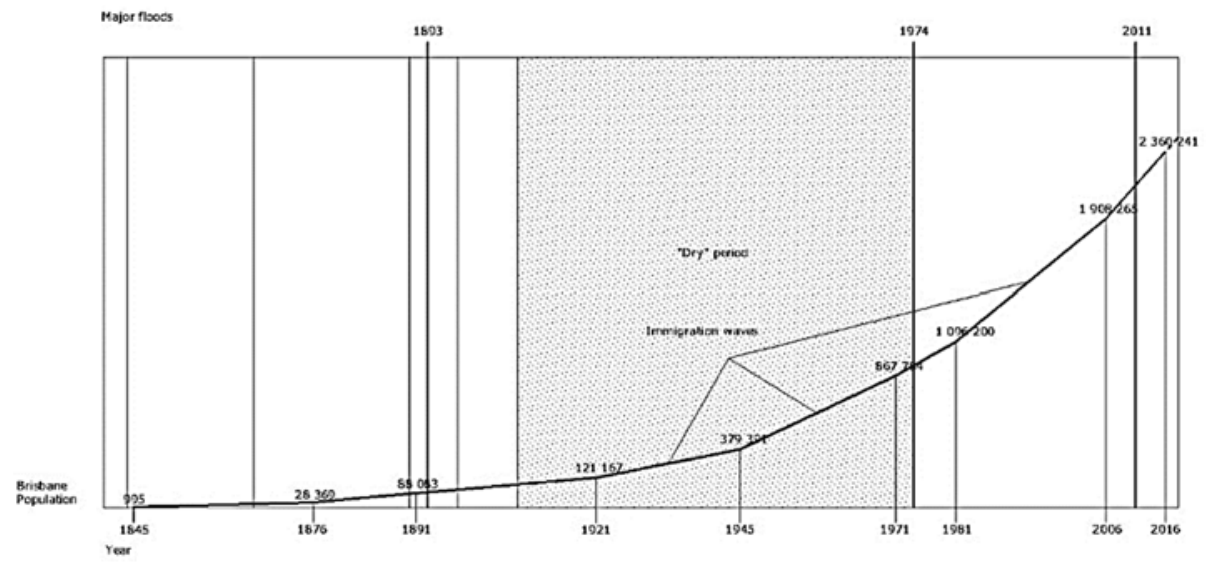

Figure 3: Population growth and major floods in Brisbane from British settlement to present. 


\section{A HISTORY OF FLOODS}

High magnitude flooding in Brisbane is either driven by decaying tropical cyclones or strong La Niña events. When continued, heavy rain, has produced catchment saturation, increased run-off contributes to river or flash flooding [20]. Flooding in Brisbane can hit in various ways: overland flow, flash flooding in creeks, river flooding, backwater flooding when creeks enter the main river course and storm surges and tidal effects from the ocean [22], [36].

Early accounts testify that the first European explorers realised soon the high flood risk associated with Australian rivers. Consequently, flood safety, together with water availability became main considerations for the location of new towns, even though subsequent land clearance may have increased flood risk exposure of some towns and cities [10], [15]. Flood records in Brisbane start in the 1840s, shortly after the British settlement was established. Two major floods took place before the turn of the century: one in 1841 and a second one in 1893. From that date until the 1974 the region was spared of major floods, which is arguably one of the reasons why the floodplain was extensively occupied and the issue of flooding disregarded (Fig. 3). It is understood that the only flood risk mitigating actions undertaken in Brisbane during that time was the trimming of point sand bars to enhance the flow of the river at bends, and commercial dredging for sand and gravel, which happened to have a flood mitigating side-effect [15].

The big flood of 1974 brought back the old flood concerns and urged a review of the city's flood risk management practices. Interestingly, conclusions of investigations following the flood included the fact that flood maps were available since at least 1944, but there was little knowledge of their existence. This is probably due to infrequent and minor floods in the Brisbane river catchment since the beginning of the twentieth century. Moreover, since 1966, there was even a flood warning system in place for the Brisbane river system that included prediction of flood height and time of occurrence at three locations on the lower part of the river. Unfortunately, both resources were underutilised by the authorities in averting the more severe impacts of the flood [22]. As a response to the 1974 floods the Wivenhoe Dam was built to perform dually as a flood mitigation device and a drinking water reservoir [22]. Following the dam completion, authorities lowered the flood datums which would prove damaging in the 2011 floods [37].

\subsection{The 2011 floods}

In the year prior to the 2011 floods, the Wivenhoe dam created the wrong perception among decision-makers and the public that flood risk in Brisbane had diminished, and even though some warned against incurring in this moral hazard, the 2011 flood impacted a city that had in fact increased the vulnerability of its building stock [20]. In this regard, the Brisbane City Council (BCC) wrongly assumed a granted percentage of flood risk reduction by the dam operation. Arguably, continuous political interference to accommodate the interests of property owners and developers made it impossible to accept more precautionary Q100 datums - which had been advised by in-house and external experts in several occasions since the completion of the dam in 1985. Thus. the BCC upheld a reduced datum with the unqualified assumption that the dam would always be operated to prioritise flood prevention over maximising storage capacity, when, in reality the opposite was true (Fig. 4). At least a lack of coordination existed between the BCC and the Queensland State Government in the priorities they assigned to the operation of the dam [18], leading to disastrous consequences for Brisbane and its inhabitants.

Van den Honert and McAneney [20] report on the 2011 Brisbane's flood that despite the Bureau of Meteorology (BOM) warnings immediately ahead of the event were sufficiently 


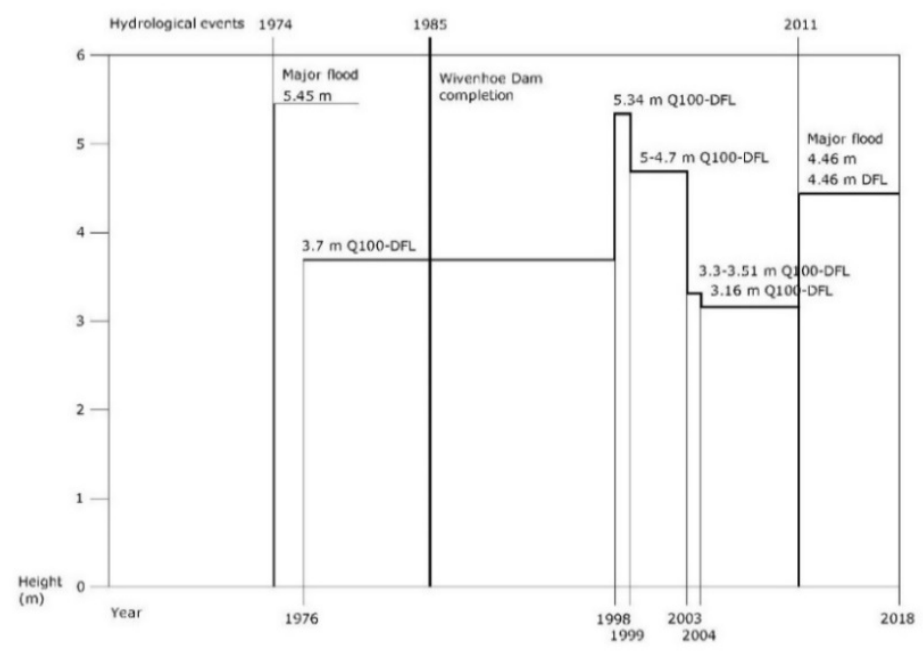

Figure 4: Brief history of Q100 estimates and Defined Flood Levels (DFL) since 1974.

accurate, the Wivenhoe dam operators neglected them. Without the aid of any decisionmaking tool to incorporate uncertainty in the predictions, they assumed a radical zero-rainfall scenario, which allowed them to keep the dam full. Although the decision was found to be lawful and within the limits of the dam procedures there was a strong sense of negligence in the behaviour of the operators [37]. In this vein, insurers concluded that it was a "dam release flood", which means that the main cause of flooding was the volume of water released by the South East Queensland Water (seqwater) engineers managing the dam [20]. Negligence though does not necessarily mean incompetence, as political pressure from the State Government may have played a part in the decision to maintain the dam at full capacity in the context of the preceding drought [18].

Even though the dam helped reduce the flood extent to a certain degree, which was smaller than that of the 1974 floods, extrapolated economic losses were greater, due to increased urban development and, arguably, its already mentioned exposure to flood risk [20]. In fact, the likely extension of floods was well known before the event, as inundation maps existed since the 1940s and no major topographical changes to the landscape of the catchment had been undertaken besides the Wivenhoe dam. Exposed buildings farther upstream from Brisbane were devastated by flash flooding waters, which were so swift as to render the existing warning systems useless, at a regrettable human cost [20]. Similar to riverine flooding SEQ's flash floods show high intensity and flow variability [8], but contrary to them, flash flooding events in the region are far more frequent and warning much more difficult. Both types of flood experienced in the city in 2011 point at the need to prioritise efforts to limit exposure of built structures and people along vulnerable creeks and overland flow paths.

\section{DISCUSSION}

\subsection{Planning after the flood}

Some planning developments in the SEQ region following the flood seemed to indicate a new attitude towards climate adaptation, including a case of relocation through a land swap 
program in Grantham, unique in the Australian context [20]. In Brisbane, a similar scheme was already in place since 2006 , but only voluntarily for homes affected by low magnitude floods [38]. This initiative though showed modest success and had little influence in mitigating the effects of the 2011 floods. Post-flood, BCC decided to raise the Defined Flood Level (DFL) for rebuilding to the 2011 peak flood level (Fig. 4). Also, the minimum habitable floor level for residential development moved to a minimum of $500 \mathrm{~mm}$ above the DFL [20]. Simultaneously, more ambitious planning instruments started to appear. First, the approval of the Temporary Planning instruments [37] led to the publication of the 2014 Brisbane City Plan, which finally included flood risk planning provisions through the Flood overlay code [36]. However, the code only uses a narrow range of flood resilience strategies, mainly aimed at flood-proofing buildings. It has been also criticised for lacking design considerations to ensure streetscape amenities, promoting green permeable surfaces and in general sustainability and liveability in flood-prone areas [39].

Despite these new policies, lack of integration and coordination between different planning spheres and instruments seems to persist in Brisbane. Neighbourhood Plans (NP) are paradigmatic of this gap. Developed by BCC with input from local communities, they are meant to guide the development of specific urban areas according to their environmental, social and economic features [40]. Remarkably though, while this is the scale of many flood management solutions, NPs do not include references to flooding, instead relying on the citywide Flood overlay code. The piecemeal approach of this document, which encourages interventions that limit their effects to individual lots, and the fragmentation of the urban network of green-infrastructure, are both expressions of the authorities' preference for a strong separation of public and private spheres [41]; this is detrimental to effective flood resilience strategies, which require comprehensive interventions across city scales and property boundaries.

\subsection{Economic and social factors}

Flood maps have been published and easily accessible online for some years, including their recent update [42]. However, insurers claimed a lack of available data on flood risk before the 2011 floods, which seems to indicate a deficit in transparency on the side of the local government. On the other hand, insurance policies were generally unclear about what type of flooding was actually covered, as it infamously surfaced after the 2011 disaster, when many homeowners discovered that their policies did not cover riverine flood losses [20]. A third issue concerning the role of insurance in flood risk management in Brisbane is that river flood insurance is not compulsory, which encourages risk-taking as it becomes economical in the short term; even the Queensland government did not have insurance cover for its own infrastructure in 2011, alleging that it was not worth the price [20].

International experience show different ways in which insurance mechanisms can be useful in reducing vulnerability of urban areas and flood losses through the distribution of recovery costs [43]. Both optional insurance and subsidised public schemes foster the perception that disasters have a low probability, indirectly promoting risk-taking [44]. In contrast, the price of private insurance for buildings tends to increase with vulnerability [45], so when risk level is effectively transferred to insurance price for properties, this in turn can promote climate-resilient architecture and urban design - as a means to reduce risk exposure and the resulting higher cost of insurance - and a trend to retreat from vulnerable areas [46].

Nevertheless, the economical approach alone is insufficient, as insurance premiums cannot cover the consequences of loss of lives and social disruption [47]. After the 2011 flood, Brisbane's neighbourhoods where people had to move out and areas where newcomers 
arrived, both became less socially resilient, as it has been observed that only stable populations significantly enable reciprocity to emerge [48]. In this sense, measures aimed at minimizing the displacement of people due to the impact of floods, such as managed retreat from vulnerable areas or flood-proofing neighbourhoods are conducive to greater social resilience to floods.

\subsection{Learning from the history of floods}

Lessons learned from the rich - yet sometimes contradictory - Brisbane's history of floods can inform future plans for its flood resilient development, mainly streaming three main planning and design objectives: achieving climate-proof development through synergy with nature and history, adopting integrated approaches, and fostering more open, transparent and participative governance. Each of these goals can trigger a variety of environmental, social and economic actions at multiple scales: the most relevant, summarised in Table 1 below, point at the rediscovery of natural environments and their preservation, and suggest a model of sustainable development based on social resilience, through participatory mechanisms, and structural resilience; this can be achieved prioritising long-term environmental choices at regional scale over short-term political convenience, and through the adoption of watersensitive design solutions to minimise and manage flood risk exposure in urban areas.

\section{CONCLUSIONS}

The system boundary of Brisbane and the SEQ region's planning and governance structure does not match the territory's deep structure: it simply ignores catchment boundaries; ecological zones limits or the Aboriginal "countries" (Fig. 2). This administrative fragmentation has driven an inconsistent management of the hydrologically complex SEQ region, with some catastrophic consequences on its natural, built and human assets. In an area of such high ecological importance, green space per capita and protected natural areas are scarce, even compared to other Australian capital cities and their regions. Environmental choices are often driven by electoral and planning cycles, which do not correspond to more powerful climatic cycles, thus future climate scenarios are not sufficiently considered as they exceed short term planning. Barriers to adoption of long term planning strategies tuned with

Table 1: Actions for climate-resilient planning in Brisbane and SEQ.

\begin{tabular}{|l|l|}
\hline GOAL & ACTION \\
\hline $\begin{array}{l}\text { 1. Climate-proof } \\
\text { development through } \\
\text { synergy with nature and } \\
\text { history }\end{array}$ & $\begin{array}{l}\text { Acquisition and dissemination of environmental knowledge } \\
\text { and awareness (deep structure); } \\
\text { Preservation of vulnerable areas from urban development; } \\
\text { Use of green infrastructure and flood-resilient technology; } \\
\text { Planning for both seasonal and long-term variability. }\end{array}$ \\
\hline $\begin{array}{l}\text { 2. Integrated planning } \\
\text { approaches }\end{array}$ & $\begin{array}{l}\text { Inclusion of sustainability and liveability considerations in } \\
\text { planning and governance policies; } \\
\text { Introduction of compulsory flood risk insurance; } \\
\text { Flood-proofing of existing and new building stock. }\end{array}$ \\
\hline $\begin{array}{l}\text { 3. Open, transparent and } \\
\text { participative governance }\end{array}$ & $\begin{array}{l}\text { Adoption of fully transparent governance; } \\
\text { Increase of accountability of decision makers; } \\
\text { Promotion of public participation for increased awareness } \\
\text { and engagement. }\end{array}$ \\
\hline
\end{tabular}


the specificity of the territory lay in the neglect of environmental knowledge, in resistant organisational structures, and in governance constraints that limit the overall capacity for evidence-based decision-making. Changing the planning and governance structure of the region to accommodate its deep structure entails two key actions: not only to acquire a better understanding of the territory and its hydrology at the regional scale, along the lines suggested here, but also (and foremost) to prioritise this knowledge at all levels of governance and planning.

\section{ACKNOWLEDGEMENTS}

The Authors want to acknowledge the advice of Professor Paul Memmott, director of the Aboriginal Environments Research Centre at the University of Queensland, and the support of the Cooperative Research Centre for Water Sensitive Design.

\section{REFERENCES}

[1] Diamond, J.M., Guns, Germs and Steel: A Short History of Everybody for the Last 13,000 Years, Vintage: London, p. 480. 1998.

[2] Durant, W. \& Durant, A., The Lessons of History, Simon \& Schuster: New York, 1968.

[3] Kaplan, R.D., The revenge of geography. Foreign Policy, 172, pp. 96-105, 2009.

[4] Boyd, R. \& Richerson, P.J., The Origin and Evolution of Cultures, Oxford Univeristy Press: New York, p. 455, 2005.

[5] Whiston Spirn, A., Ecological Urbanism: A Framework for the Design of Resilient Cities, p. 35, 2012.

[6] Dickinson, G. \& Murphy, K., Ecosystems. Environmental Science Texts, ed. R. Gardner \& A.M. Mannion, Routledge: Oxon, p. 205, 2007.

[7] Zevenbergen, C. et al., Urban Flood Management, CRC Press/Balkema: Leiden, p. $322,2011$.

[8] Fryirs, K., Lisenby, P. \& Croke, J., Morphological and historical resilience to catastrophic flooding: The case of Lockyer Creek, SE Queensland, Australia. Geomorphology, 241, pp. 55-71, 2015.

[9] Clarkson, C. et al., Human occupation of northern Australia by 65,000 years ago. Nature, 547, p. 306-310, 2017.

[10] Freestone, R., Urban Nation, CSIRO Publishing: Victoria, Australia, 2010.

[11] Kemp, J. et al., River response to European settlement in the subtropical Brisbane River, Australia. Anthropocene, 11, p. 48-60, 2015.

[12] Spearritt, P., The $200 \mathrm{~km}$ city: Brisbane, the Gold Coast, and Sunshine Coast. Australian Economic History Review, 49(1), p. 87-106, 2009.

[13] Meerow, S., Newell, J.P. \& Stults, M., Defining urban resilience: A review. Landscape and Urban Planning, 147, p. 38-49, 2016.

[14] Webb, R. \& Beh, J.-L., Leading Adaptation Practices and Support Strategies for Australia: An International and Australian Review of Products and Tools, National Climate Change Adaptation Research Facility: Gold Coast, p. 120, 2013,

[15] Denham, P. et al., The River: A History of Brisbane, Museum of Brisbane: Brisbane, 2013.

[16] Heads, M., Biogeography of Australasia: A Molecular Analysis, Cambridge University Press: Cambridge, p. 494, 2014.

[17] Burbidge, N.T., The Phytogeography of the Australian Region, University of Western Australia: Canberra, p. 137, 1960. 
[18] Tangney, P., Brisbane City Council's Q100 assessment: How climate risk management becomes scientised. International Journal of Disaster Risk Reduction, 14, pp. 496503, 2015.

[19] Kozlowski, M. \& Yusof, Y.M., The role of urban planning and design in responding to climate change: The Brisbane experience. International Journal of Climate Change Strategies and Management, 8(1), p. 80-95, 2016.

[20] Van den Honert, R.C. \& McAneney, J., The 2011 Brisbane floods: Causes, impacts and implications. Water, 3(4), pp. 1149-1173, 2011.

[21] Hamnett, S., Brisbane. City Profile, pp. 442-448, 1984.

[22] Bureau of Meteorology, Brisbane Floods, January 1974. Report by Director of Meteorology, D. of Science: Canberra, p. 63, 1974.

[23] Tooth, S. \& Nanson, G.C., The geomorphology of Australia's fluvial systems: retrospect, perspect and prospect. Process in Physical Geography, 19(1), pp. 35-60, 1995.

[24] Croke, J. et al., Macrochannels and their significance for flood-risk minimisation: examples from southeast Queensland and New South Wales, Australia. Stochastic Environmental Research and Risk Assessment, 28, pp. 99-112, 2013.

[25] Neil, D.T. et al., Sediment yield and impacts from river catchments to the Great Barrier Reef lagoon. Marine and Freshwater Research, 53(4), pp. 733-752. 2002.

[26] Stimson, R.J. \& Taylor, S.P., Brisbane. City Profile, 16(4), pp. 285-295, 1999.

[27] O'Hare, D. \& Hefferan, M., Creating a sustainable Sunshine Coast: The potential contribution of an expanded Sippy Downs, 17, 2007.

[28] Laudine, C., Aboriginal Environmental Knowledge: Rational Reverence, Ashgate: Burlington, p. 187, 2009.

[29] MacMahon, B. \& Finnerty, A., The Architecture of East Australia: An Architectural History in 432 Individual Presentations, Edition Axel Menges: Stuttgart, p. 251, 2001.

[30] Gillen, M., The challenge of attaining a sustainable urban morphology for South East Queensland. Planning Practice and Research, 21(3), pp. 291-308, 2006.

[31] Searle, G., Too concentrated? The planned distribution of residential density in SEQ. Australian Planner, 47(3), pp. 135-141, 2010.

[32] Australian Bureau of Statistics, QuickStats 2011. Online. www.abs.gov.au/ websitedbs/censushome.nsf/home/quickstats?opendocument\&navpos=220.

[33] De Manincor, J., SILT. Architecture Australia, p. 50-56, 2014.

[34] The State of Queensland, South East Queensland Regional Plan 2009-2031, D.o.I.a. Planning, Queensland Government: Brisbane, p. 173, 2009.

[35] Queensland Government, Shaping SEQ: South East Queensland Regional Plan 2017, L.G.a.P. Department of Infrastructure, Department of Infrastructure, Local Government and Planning: Brisbane, p. 191, 2017.

[36] Brisbane City Council, Brisbane City Plan 2014, Brisbane City Council: Brisbane, 2014.

[37] Davidson, C., Amphipious Brisbane: A critical comparison of five post-flood houses in Brisbane city, School of Architecture, The University of Queensland: Brisbane, $p$. 65, 2015.

[38] Brisbane City Council, Brisbane's Floodsmart Future Strategy 2012-2031, Brisbane City Council: Brisbane, 2015.

[39] Leardini, P. et al., Dwelling at the water's edge: An investigation into multi-residential development and flood resilience in Brisbane, Australia. 9th International Urban Design Conference Canberra, 2016. 
[40] Brisbane City Council, Neighbourhood planning and urban renewal. Online. www.brisbane.qld.gov.au/planning-building/planning-guidelines-tools/ neighbourhood-planning-urban-renewal. Accessed on: 6 Mar. 2018.

[41] Leardini, P., Brage, T. \& Bowstead, S., A Flood Resilience Manifesto: Reframing Brisbane City's High Density Waterfront Development, in Living and Sustainability: An Environmental Critique of Design and Building Practices, Locally and Globally, London South Bank University: London, p. 15, 2017.

[42] Brisbane City Council, Flood Awareness Map, 2017.

[43] Dávila, O.G. et al., Promoting resilient economies by exploring insurance potential for facing coastal flooding and erosion: Evidence from Italy, Spain, France and United Kingdom. Coastal Engineering, 87, pp. 183-192, 2014.

[44] McGuire, C.J., U.S. coastal flood insurance, risk perception, and sea-level rise: A perspective. Coastal Management, 43(5), pp. 459-464, 2015.

[45] Hansen, H.S., Modelling the future coastal zone urban development as implied by the IPCC SRES and assessing the impact from sea level rise. Landscape and Urban Planning, 98(3-4), pp. 141-149, 2010.

[46] Deloitte, Building Our Nation's Resilience to Natural Disasters, Barton, p. 92, 2013.

[47] Doornkamp, J.C., Coastal flooding, global warming and environmental management. Journal of Environmental Management, 52, pp. 327-333, 1998.

[48] Wickes, R., Britt, C. \& Broidy, L., The resilience of neighborhood social processes: A case study of the 2011 Brisbane flood. Soc. Sci. Res., 62, pp. 96-119, 2017. 